\title{
Recognising and responding to acutely deteriorating women in New Zealand maternity wards: A literature and environmental scan
}

Leona Dann ${ }^{A, B}$ DHSC, MMid (Hons), RM, RN • Jennifer Hill ${ }^{B}$ MHR (Hons), PG Dip (Critical Care Nursing), BN

${ }^{\mathrm{A}}$ Corresponding

Author: leona.dann@ hqsc.govt.nz

${ }^{\text {B }}$ Health Quality \& Safety Commission, Wellington

\begin{abstract}
Background: A significant body of evidence now demonstrates that early warning, recognition and response systems can help to prevent harm associated with in-hospital clinical deterioration. Systems for early recognition of, and response to, pregnant or recently pregnant ( $<42$ days) women whose conditions are acutely deteriorating in hospital maternity settings have been recommended in other countries as a useful way of supporting rapid intervention and treatment, but it was not known what systems were in place in New Zealand (NZ) hospitals. The Maternal Morbidity Working Group (MMWG), within the Perinatal and Maternal Mortality Review Committee, has recommended the development of a national approach to detecting and responding to acute deterioration in inpatient pregnant women to align with the national patient deterioration programme currently in implementation.
\end{abstract}

Aim: The aim of this project was to investigate current practice nationally and internationally, by identifying the evidence related to early warning systems and tools, and investigating current models in place at NZ district health boards (DHBs) that support the early identification and treatment of an inpatient pregnant woman's deteriorating condition.

Method: We performed a literature search and environmental scan. The search strategy incorporated both academic and grey literature databases using the same search terms. The environmental scan involved contact with all NZ DHB midwifery leaders to request information on early warning systems and tools currently in use.

Findings: Sixteen papers met the inclusion criteria for the literature scan. The majority of evidence about the role of maternal early warning systems in preventing morbidity comes from retrospective case reviews, retrospective cohort studies, cross-sectional surveys, and validation studies, with some prospective evidence where early warning systems were evaluated after implementation. There were some indications that early warning systems can contribute to earlier identification of deterioration and cost-effectively reduce harm, although there is wide variation in the parameters used. The environmental scan found that 15 of the $17 \mathrm{DHB}$ maternity services who responded (from 20 total services) have introduced, or are in the process of introducing, modified obstetric early warning systems. There is wide variation in the designs, parameters and thresholds of these scores, as well as the recognition and response systems in use.

Conclusion: A substantial proportion of DHBs are developing and implementing tools and early warning systems for maternity care. There is significant variation in the tools and approaches in current use. The MMWG and the Health Quality \& Safety Commission have recommended development of a nationally standardised recognition and response system for use in NZ hospitals for pregnant or recently pregnant ( $<42$ days) women to align with the national patient deterioration programme.

Keywords: maternity, early warning, track and trigger tools, recognition and response, score, system, physiological deterioration

\section{INTRODUCTION}

Most women are healthy throughout their pregnancies but, for a small number, pregnancy will be complicated by a significant morbidity experience. It is estimated that approximately $1 \%$ of all births in England are severely complicated (Waterstone, Bewley, \& Wolfe, 2001), although that is thought likely to underestimate the current United Kingdom (UK) situation (Knight et al., 2016). Maternal morbidity review is a quality improvement initiative that seeks to identify ways to improve systems and processes so that fewer women become seriously unwell during pregnancy or within 42 days of birth.

Systems for early recognition of, and response to, women whose conditions are acutely deteriorating in hospital have been identified as a useful way of supporting rapid intervention and treatment. Earlier recognition and appropriate response has the potential to reduce the physical and psychological severity of episodes of acute 
deterioration experienced by women, thereby enhancing their recovery from childbirth and transition to motherhood.

It is now well established that in-hospital serious adverse events such as unexpected death and cardiac arrest are often preceded by observable physiological and clinical abnormalities (Buist, Bernard, Nguyen, Moore, \& Anderson, 2004; McQuillan et al., 1998; Schein, Hazday, Pena, Ruben, \& Sprung, 1990). Failures to recognise and respond to such abnormalities are preventable errors that can have devastating consequences for patients, families, whānau, and clinicians. A significant body of evidence now demonstrates that recognition and response systems can help to prevent harm associated with in-hospital clinical deterioration and have demonstrated improved outcomes in general adult populations internationally (Andersen et al., 2016; Ludikhuize et al., 2015; National Institute for Health and Care Excellence, 2007; Pain et al., 2016; Schein et al., 1990; Winters et al., 2013). The Health Quality \& Safety Commission (the Commission) is currently implementing a national patient deterioration programme for non-pregnant adult patients.

Anecdotal evidence from clinicians has suggested that early warning systems in maternity settings are currently being developed and used in some District Health Boards (DHBs), with significant variation in the tools and approaches in use and equivocal evidence of benefit. It is proposed that work to standardise maternity early warning systems in New Zealand (NZ) is aligned with the adult programme to ensure a sustainable and cohesive approach to implementation of systems to recognise and respond to acute deterioration in hospital. There was uncertainty over which, and to what level, early warning systems had been introduced into maternity settings in NZ and therefore there was a need to identify current practice.

\section{AIM}

The aim of this project was twofold: firstly, to identify and summarise the evidence related to early warning systems and tools that may support early identification of, and response to, episodes of acute deterioration experienced by pregnant or recently pregnant women within inpatient settings. Secondly, the aim was to identify if and how any of these tools have been incorporated into practice within the maternity hospital setting in NZ.

\section{METHODS}

A literature search was undertaken to summarise available evidence about existing early warning systems from both academic and grey literature databases. An environmental scan was conducted to understand the current NZ context.

\section{Search strategy}

Ministry of Health librarians assisted with a literature search strategy using terms agreed by the authors. The search strategy (Table 1) incorporated both academic and grey literature databases using the same search terms (although the search strategy was modified to accommodate the limitations of grey literature search engines, the keywords used were the same).

\section{Environmental scan}

There are $20 \mathrm{DHB}$ in NZ and midwifery leaders for each of these DHBs were contacted by email (by LD) with a request to provide the authors with information on what early warning systems and tools were currently in use in their maternity service. These leaders were also asked to forward a copy of any relevant DHB maternity policy or guideline and vital sign charts being used in their service.

\section{Table 1. Search strategy}

Academic Ovid MEDLINE(R) Epub Ahead of Print, In-Process \& Other database Non-Indexed Citations

search Ovid MEDLINE(R) Daily

engines

Ovid MEDLINE and Versions(R)

Ovid Nursing Database < 1946 to June Week 3 2017>

CINAHL

PubMed

Scopus

Grey $\quad$ Australia Policy Online

literature Canadian Electronic Library

Google (with a focus on non-governmental organisations, government, and academic websites)

Greynet

Health Foundation Archives

King's Fund Library

NICE evidence Search

Opengrey

TRIP (Turning Research into Practice) database, GreyLit

Inclusion Full text

criteria In English

First world (Europe, UK, Ireland, Canada, Australia, NZ, USA)

Peer reviewed academic journals

Policy and other grey literature

Exclusion Editorials

criteria Commentary

Conference proceedings

Posters

\section{Search terms}

1 (matern* or perinatal or pregnan* or obstetric*).mp

2 (fatality or mortality or morbidity or (deteriorat* adj3 patient*) or "acute deterioration" or "clinical deterioration" or "physiological deterioration" or "preventable death").mp.

$3 \quad 1$ and 2 (79276)

$4 \quad$ (|"early warning" or "patient safety" or "early detection" or "vital sign*" or "observations" or "emergency response" or "rapid response") adj5 (system* or score* or criteria or tool*)l.mp.

5 ("track and trigger" or "recogni* AND respon*").mp. [mp=ti, ab, ot, nm, hw, kf, px, rx, ui, sy, dw]

3 and (4 or 5)

limit 6 to English language

limit 7 to $y r=" 2012-C u r r e n t "$

remove duplicates from 8

10 limit 9 to (comment or editorial or letter)

119 not 10

\section{Supplemental search based on keyword review}

1 ((matern* or perinatal or pregnan* or obstetric*) adj5 ("early warning" or "patient safety" or "early detection" or "vital sign*" or "observations" or "emergency response" or "rapid response" or "track and trigger" or "recogni* and respon*") adj5 (system* or score* or criteria or tool*)).mp. [mp=ti, ab, ot, nm, hw, kf, px, rx, vi, sy, dw]

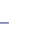

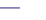




\section{A note on terminology}

One of the difficulties of interpreting the findings of the literature on maternity early warning systems is a lack of clarity and consistency around the use of terms to describe the tools and processes that are reported. Of particular note is the interchangeable use of the acronym "EWS" to describe, variously, early warning scores and early warning systems.

In the non-pregnant adult literature, the term "early warning score" specifically refers to aggregate weighted early warning scores derived from vital sign data. These rely on the calculation of scores that are assigned to individual vital sign abnormalities, with the aggregated total score triggering action. Other trigger tools require action to be taken when single vital sign parameter thresholds that indicate abnormality are breached. The New Zealand Early Warning Score (NZEWS) for non-pregnant adults is a combination system that includes an aggregate weighted score, and single parameter triggers for high levels of abnormality (Health Quality \& Safety Commission, 2017).

In the non-pregnant adult literature, early warning systems specifically refer to the use of a track and trigger tool (such as an early warning score or single parameter trigger tool), the accompanying escalation pathway and response processes, and the organisational structures and supports required to ensure the system is sustainable and effective. These commonly include structures and processes for ongoing clinical governance, monitoring and improvement, communication and team work, and education and training.

Further confusion is added when various acronyms (for example MEWT, MEOWS, MEWS) are used to refer to either aggregate early warning scores or single parameter trigger tools with little differentiation. This requires particular attention when attempting to interpret available evidence and weigh up the potential risks and benefits of using one method to support recognition of deterioration over another.

\section{FINDINGS}

\section{Literature scan}

As illustrated in Figure 1, a total of 175 abstracts were retrieved from the academic database searches, with an additional 11 items retrieved from grey literature sources. After abstract review, 133 items were excluded, and the full text for the remaining 46 papers and 4 grey literature items was reviewed. A further 26 items did not meet the inclusion criteria that studies dealt specifically with maternity settings, early warning, and track and trigger systems. Twenty papers and grey literature items met the search criteria and were reviewed. A further four were then excluded; three that were expert opinions and one that discussed early warning systems in a third world country.

The available evidence about the role of maternal early warning systems in preventing morbidity is generally not robust. Pragmatically, randomised controlled trials are not available, and the majority of evidence comes from retrospective case reviews, retrospective cohort studies, cross-sectional surveys, and validation studies, with some prospective evidence where early warning systems were evaluated after implementation. See Table 2 for study designs, methods, settings and findings.

Despite some indications that early warning systems can contribute to earlier identification of deterioration (Carle, Alexander, Columb, \& Johal, 2013; Shields, Wiesner, Klein, Pelletreau, \& Hedriana, 2016), the majority of available studies have attempted to validate the use of maternity early warning tools, scores and triggers only in specific populations of women (Edwards et al.,

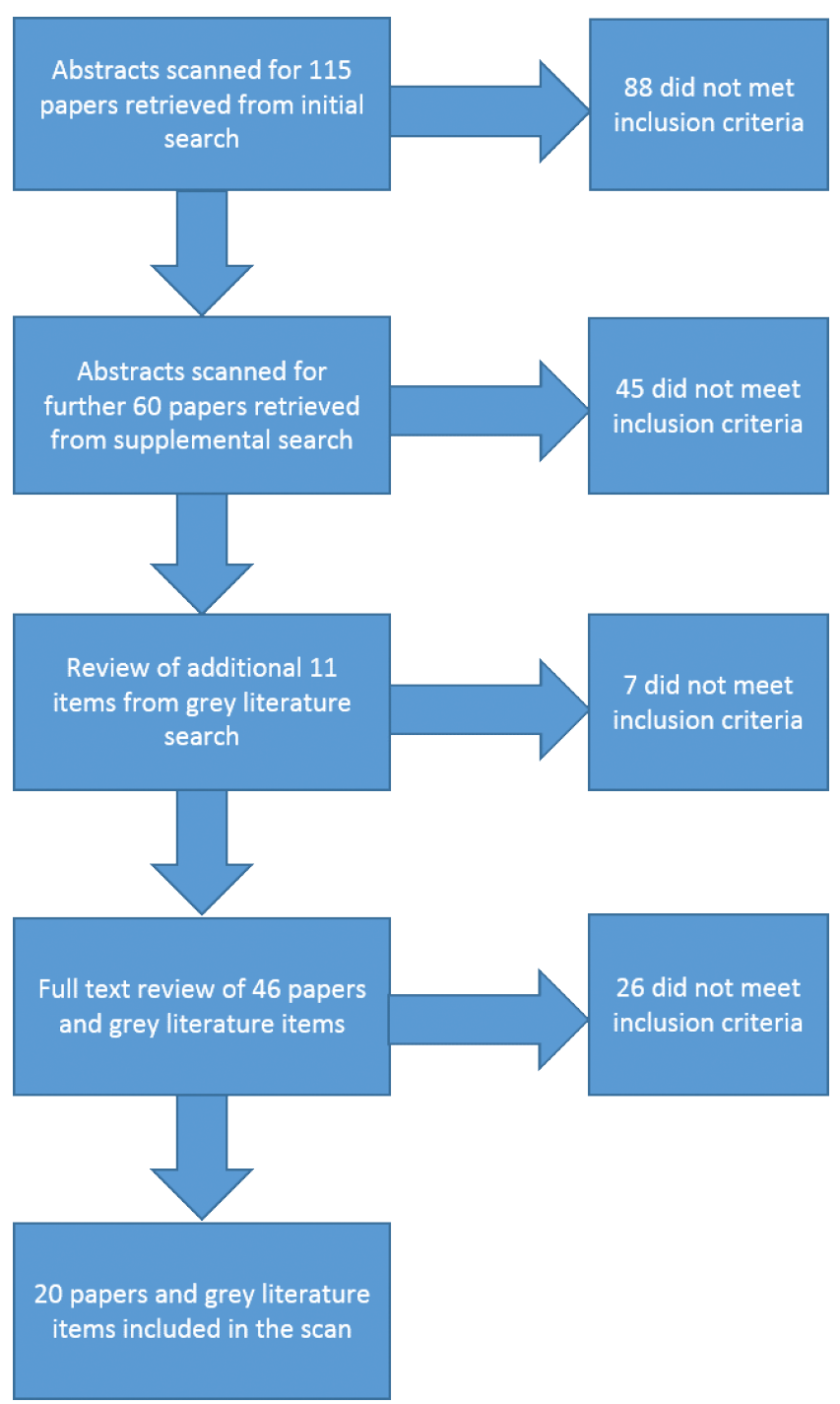

Figure 1. Academic and grey literature search findings

2015; Maguire et al., 2016). This limits our understanding of how effective such tools are in a general population of hospitalised women in the maternity context. However, there are indications that implementing a maternity early warning system can costeffectively reduce harm from maternal morbidity in hospitalised women (Hedriana, Wiesner, Downs, Pelletreau, \& Shields, 2016; Hess, Hoffmann, Shields, \& Caughey, 2017). It is clear that there is wide variation in the parameters used as part of an early warning tool (for example, respiratory rate, heart rate, proteinuria or lochia), and in the specific trigger thresholds within each parameter; for example, a respiratory rate of 25 may indicate abnormality in one tool but be considered normal in another (Bick et al., 2014; Smith et al., 2017). Such variation highlights the potential difficulty of reaching agreement on the most sensitive and specific parameters, thresholds and tools to detect deterioration, and also highlights the potential for confusion and delays in recognising deterioration. Further confusion about the effectiveness of early warning systems in maternity settings is incurred when considering the varying practices around the timing and application of early warning tool use. For example, in some cases they are used only when a woman has already been identified as "at risk"; in others they are meant to be used for all pregnant women, and in yet others for all women more than 20 weeks pregnant. 
Despite equivocal evidence about the validity and impact of introducing maternity early warning systems, a number of jurisdictions have made recommendations for their implementation. For example, in the UK, the Centre for Maternal and Child Enquiries (2011) recommends that all maternity services implement a maternity early warning tool. In Ireland, the National Clinical Effectiveness Committee (2014) recommends the standardised Irish Maternity Early Warning System (IMEWS) and has developed guidance about its implementation. Similarly, in California, the Council on Patient Safety in Women's Health Care developed maternal early warning criteria and provides guidance around the development of escalation pathways (Council on Patient Safety in Women's Health Care, 2017). The Australian National Safety and Quality Health Service Standards also require health services to have recognition and response systems in place, including in maternity services (Australian Commission on Safety and Quality in Health Care, 2012).

However, implementation of maternity early warning systems may not be straightforward. A grounded theory study in the UK identified perceived barriers to the use of early warning systems among midwives and obstetricians (Mackintosh, Watson, Rance, $\&$ Sandall, 2014). There was a view that using early warning systems with every woman created additional workload without clear benefit. There was also a view among the interviewed midwives that early warning systems threatened their ability to apply clinical judgment in the care of women experiencing episodes of acute deterioration. The authors further identified the significance to implementation and change management of "cultures, boundaries and hierarchies within midwifery teams, between obstetricians and physicians and between midwives and physicians"(p.32).

\section{Environmental scan}

An environmental scan of $20 \mathrm{DHB}$ maternity services in NZ was undertaken, with 17 of the current $20 \mathrm{DHB}$ s responding to a request for information about current use of maternity early warning systems. Fifteen of the DHBs who responded have introduced, or are in the process of introducing, modified obstetric early warning scores. Of the 17 , two have recently developed policies and charts that are currently under trial, while another is in the process of modifying an Australian version of a maternity early warning chart and escalation process. The remaining 14 have a tool that is used, although not all have an associated policy or guideline.

There is wide variation in the designs of the maternity early warning systems in place. Despite some synergies on parameters used, tools are commonly complex in design, with variations in regard to the thresholds, triggers and escalation pathways used to support early recognition and response to acute maternal deterioration. It appears that none of the current systems has undergone robust evaluation of its effectiveness or impact on outcomes for women who deteriorate while in hospital. This variation in the recognition and response systems in use could provide the potential for confusion among clinicians working in maternity settings, particularly for lead maternity carers (LMCs) and locum clinicians who work across multiple DHBs.

\section{DISCUSSION}

The aim of this literature and environmental scan was to summarise the evidence that supports the use of early warning systems within the maternity sector and, secondly, to identify if the NZ maternity inpatient services had introduced early warning systems.

We found equivocal evidence as to the benefit of early warning systems due to a lack of robust, high level evidence and wide variation in the tools, parameters and thresholds used to detect deterioration. Despite this, many countries have developed and implemented early warning systems as quality improvement initiatives. NZ has a unique model of maternity care because of the role of the LMC in delivering continuity of care. Other countries where early warning maternity systems have been implemented may have different models of care that could impact on the applicability of the international literature in the NZ setting.

The majority (14 out of the 17 we heard from) of the DHBs within NZ have already developed and implemented early warning systems as a means of identifying women experiencing an episode of acute deterioration within maternity wards. A further three are in the process of developing, testing or implementing early warning systems. This means that despite a lack of robust evidence, there has been a pragmatic approach to implementing systems in each DHB to support the recognition of, and response to, pregnant and postnatal women whose conditions are acutely deteriorating. However, the pragmatic approach has led to wide variation in the parameters, thresholds, escalation and documentation processes used across NZ maternity services.

Such variation creates risk in a small country such as NZ, where LMCs may work in multiple DHBs, and locum maternity clinicians are common. A nationally standardised early warning system would reduce the potential for confusion about the early warning system in use; provide opportunities to streamline training and education, including at the undergraduate level; and potentially smooth referral processes for women whose conditions are deteriorating and require transfer between services. An additional benefit is the opportunity to also instigate a change in culture, developing escalation processes that reflect respectful interdisciplinary discourse and facilitate appropriate and timely assessment of affected women by a clinician with the necessary skills.

The Commission and the Maternal Morbidity Working Group (MMWG) have identified the need to ensure that there is a consistent and agreed approach to support appropriate recognition of deterioration and timely escalation of care. The group has identified a need to develop a national early warning system that can be used across DHBs, and that reduces ambiguity and aligns the national deteriorating patient early warning and recognition and response system with that for pregnant or recently pregnant women accessing inpatient maternity services.

The Ministry of Health also has a vested interest in furthering the development of a standardised maternity early warning tool through the continued implementation of a national maternity record. A national early warning tool and localised escalation pathways that reflect the context of maternity care in NZ are required for this national record.

The development of a maternity early warning system must be cognisant of the roles of all clinicians involved in maternity care, who have a professional responsibility to advocate for women's decisions within the complexity of the maternity service environment. Although the intent is that early warning systems are used in hospital contexts, the crucial role of the LMC in detecting deterioration must be recognised. Indeed, the Midwifery Council of New Zealand's Scope of Practice (2010) states: "The midwife understands, promotes and facilitates the physiological processes of pregnancy and childbirth, identifies complications that may arise in mother and baby, accesses appropriate medical assistance, and implements emergency measures as necessary." Furthermore, Standard Six of the New Zealand College of Midwives' Standards of Practice (2015, p.23) states: "Midwifery actions are prioritised 
and implemented appropriately with no midwifery action or omission placing the woman at risk." All clinicians working in maternity services provide care in environments that are complex, unpredictable and uncertain and they share the same intentions of achieving the best possible outcome for women and their babies.

Any national maternity early warning system should complement the autonomy and critical thinking of clinicians; it should not remove or replace the importance of professional care or clinical judgement. Rather, it should provide a safety net so that when a woman becomes unwell, her deterioration is recognised, and care promptly escalated to an appropriately skilled responding clinician and service.

Many existing tools, both nationally and internationally, are extremely complicated and visually busy. Considerations of ease of usability to minimise complexity and additional workload, also known as "human factors design" (Patel \& Kannampallil, 2014) should inform continued development of a national tool. The scope of the work should be to develop a maternity early warning tool strongly focussed on the detection of deterioration, rather than a general observation chart that factors in all potential antepartum and postpartum monitoring and assessment requirements. It is furthermore critical that appropriate governance, measurement and supporting frameworks are in place to support implementation and improvement to ensure the best possible outcomes for women and their babies.

This work will require continued input from key stakeholder representatives. In the absence of a clear evidence base, consensus about the parameters and thresholds indicating deterioration is essential. Testing of a proposed tool in appropriate maternity settings for usability continues and it will be refined as necessary. Appropriate subsequent audit and evaluation of performance will also be vital to ensure an early warning system that is fit for purpose within the NZ model of maternity care.

Our literature and environmental scan found a substantial proportion of DHBs are developing and implementing tools and early warning systems for maternity care. There is significant variation in the tools and approaches in current use and equivocal evidence of benefit. The MMWG and the Commission have recommended development of a nationally standardised recognition and response system for use in NZ hospital-based maternity services to align with the national patient deterioration programme.

Developing a nationally consistent approach to maternity early warning systems will support consistency for clinicians, regardless of which DHB they work within, and will assist DHBs to reduce the harm caused by delayed recognition of, and response to, morbidity among women who are pregnant or recently pregnant. A nationally standardised maternity early warning system would reduce the potential for confusion while providing opportunities to streamline training and education, and potentially smooth referral processes for women who require transfer between services. An additional benefit is the opportunity to foster a clinical culture of respectful interdisciplinary discourse that facilitates appropriate and timely assessment of women whose conditions are deteriorating by a clinician with the necessary skills.

\section{CONFLICT OF INTEREST DISCLOSURE}

The authors declare that there are no conflicts of interest.

\section{REFERENCES}

Andersen, L.W., Kim, W.Y., Chase, M., Berg, K.M., Mortensen, S.J., Moskowitz, A., ...Donnino, M.W. (2016). The prevalence and significance of abnormal vital signs prior to in-hospital cardiac arrest. Resuscitation, 98, 112-117.
Austin, D.M., Sadler, L., McLintock, C., McArthur, C., Masson, V., Farquhar, C., \& Rhodes, S. (2014). Early detection of severe maternal morbidity: A retrospective assessment of the role of an Early Warning Score System. Australian \& New Zealand Journal of Obstetrics \& Gynaecology 54(2), 152-155.

Australian Commission on Safety and Quality in Health Care. (2012). National Safety and Quality Health Service Standards (September 2012). Sydney, Australia: Author.

Behling, D.J., \& Renaud, M. (2015). Development of an obstetric vital sign alert to improve outcomes in acute care obstetrics. Nursing for Women's Health 19(2), 128-141.

Bick, D.E., Beake, S., Hundley, V., van Tiejlingen, E., Sheppard, Z.A., Thomas, S., . . . Smith, G.B. (2014). A national cross sectional survey of heads of midwifery services of uptake, benefits and barriers to use of obstetric early warning systems (EWS) by midwives. Midwifery, 30(11), 1140-1146.

Buist, M., Bernard, S., Nguyen, T.V., Moore, G., \& Anderson J. (2004). Association between clinically abnormal observations and subsequent inhospital mortality: A prospective study. Resuscitation, 62, 137-141.

Carle, C., Alexander, P., Columb, M., \& Johal, J. (2013). Design and internal validation of an obstetric early warning score: Secondary analysis of the Intensive Care National Audit and Research Centre Case Mix Programme database. Anaesthesia, 68(4), 354-367.

Centre for Maternal and Child Enquiries. (2011). Saving Mothers' Lives report. British Journal of Obstetrics Gynaecology, 118(supplementary), 1-203. Council on Patient Safety in Women's Health Care. (2017).

Maternal Early Warning Criteria. Retrieved 6/7/2017, from http:// safehealthcareforeverywoman.org/patient-safety-tools/maternal-earlywarning-criteria/

Edwards, S.E., Grobman, W.A., Lappen, J.R., Winter, C., Fox, R., Lenguerrand, E., \& Draycott, T. (2015). Modified obstetric early warning scoring systems (MOEWS): Validating the diagnostic performance for severe sepsis in women with chorioamnionitis. American Journal of Obstetrics and Gynecology, 212(4), 536.e1-8.

Health Quality \& Safety Commission. (2017). New Zealand Early Warning Score Vital Sign Chart User Guide 2017. Retrieved from www.hqsc.govt.nz

Hedriana, H.L., Wiesner, S., Downs, B.G., Pelletreau, B., \& Shields, L.E. (2016). Baseline assessment of a hospital-specific early warning trigger system for reducing maternal morbidity. International Journal of Gynaecology \& Obstetrics, 132(3), 337-341.

Hess, L., Hoffmann, S., Shields, L.E., \& Caughey, A.B. (2017). Costeffectiveness analysis of maternal early warning trigger tool to reduce maternal morbidity and mortality. American Journal of Obstetrics \& Gynecology, 216, S252-S252.

Isaacs, R.A., Wee, M.Y., Bick, D.E., Beake, S., Sheppard, Z.A., Thomas, S., ...Thomas, P.W. (2014). A national survey of obstetric early warning systems in the United Kingdom: Five years on. Anaesthesia 69(7), 687-692. Knight, M., Acosta, C., Brocklehurst, P., Cheshire, A., Fitzpatrick, K., Hinton, L.,... Shah, A. (2016). Beyond maternal death: Improving the quality of maternal care through national studies of 'near-miss' maternal morbidity. Programme Grants for Applied Research, 4(9), 1-180.

Ludikhuize, J., Brunsveld-Reinders, A., Dijkgraaf, M., Smorenburg, S., de Rooij, S., Adams, R., ... Cost and Outcomes of Medical Emergency Teams Study Group. (2015). Outcomes Associated With the Nationwide Introduction of Rapid Response Systems in The Netherlands. Critical Care Medicine, 43(12), 2544-2551.

Mackintosh, N., Watson, K., Rance, S., \& Sandall, J. (2014). Value of a modified early obstetric warning system (MEOWS) in managing maternal complications in the peripartum period: An ethnographic study. BMJ Quality \& Safety, 23(1), 26-34.

Maguire, P.J., O'Higgins, A.C., Power, K.A., Daly, N., McKeating, A., Turner, M.J. (2015). Maternal bacteremia and the Irish maternity early warning system. International Journal of Gynaecology \& Obstetrics, 129(2), 142-145.

Maguire, P.J., Power, K.A., Daly, N., Farren, M., McKeating, A., \& Turner, M.J. (2016). High dependency unit admissions during the first year of a national obstetric early warning system. International Journal of Gynaecology \& Obstetrics, 133(1), 121-122.

Martin, R.L. (2015). Midwives' experiences of using a modified early obstetric warning score (MEOWS): A grounded theory study. Evidence Based Midwifery, 13(2), 59-65.

McQuillan, P., Pilkington, S., Allan, A., Taylor, B., Short, A., Morgan, G., ...Collins, C.H. (1998). Confidential inquiry into quality of care before admission to intensive care. BMJ, 316, 1853-1858. 
Midwifery Council of New Zealand. (2010). Midwifery (Scope of Practice) Notice 2010. Retrieved from https://www.midwiferycouncil. health.nz/midwives/midwifery-scope-practice

National Clinical Effectiveness Committee. (2014). Sepsis Management National Clinical Guideline 6. Ireland: Department of Health.

National Institute for Health and Care Excellence. (2007). Acutely ill patients in hospital: Recognition of and response to acute illness in adults in hospital. London, UK: Author.

New Zealand College of Midwives. (2015). Midwives Handbook for Practice. Christchurch, NZ: Author. Retrieved from https://www. midwife.org.nz/quality-practice/standards-of-practice

Pain, C., Green, M., Duff, C., Hyland, D., Pantle, A., Fitzpatrick, K., \& Hughes, C. (2017). Between the flags: Implementing a safety-net system at scale to recognise and manage deteriorating patients in the New South Wales Public Health System. International Journal for Quality in Health Care, 29(1), 130-136.

Patel, V.L., \& Kannampallil T.G. (2014). Human factors and health information technology: Current challenges and future directions. IMIA Yearbook of Medical Informatics, 9, 58-66.

Ryan, H.M., Jones, M.A., Payne, B.A., Sharma, S., Hutfield, A.M., Lee, T., ... von Dadelszen, P. (2017). Validating the performance of the modified early obstetric warning system multivariable model to predict maternal intensive care unit admission. Journal of Obstetrics and Gynaecology Canada, 39(9), 728-733.e3.

Schein, R.M., Hazday, N., Pena, M., Ruben, B.H., \& Sprung, C.L. $(1990)$. Clinical antecedents to in-hospital cardiopulmonary arrest. Chest, 98, 1388-1392.
Shields, L.E., Wiesner, S., Klein, C., Pelletreau, B., \& Hedriana, H.L. (2016). Use of Maternal Early Warning Trigger tool reduces materna morbidity. American Journal of Obstetrics \& Gynecology, 214(4), 527. e521-526.

Singh, S., McGlennan, A., England, A., \& Simons, R. (2012). A validation study of the CEMACH recommended modified early obstetric warning system (MEOWS). Anaesthesia, 67(1), 12-18.

Smith, G.B., Isaacs, R., Andrews, L., Wee, M. Y., Van Teijlingen, E., Bick, D. E., \& Hundley, V. (2017). Vital signs and other observations used to detect deterioation in pregnant women: An analysis of vital sign charts in consultant-led UK maternity units. International Journal of Obstetric Anesthesia, 30, 44-51.

Waterstone, M., Bewley, S., \& Wolfe, C. (2001). Incidence and predictors of severe obstetric morbidity: Case-control study. $B M J$, 322(7294), 1089-1093; discussion 1093-1084.

Winters, B.D., Weaver, S.J., Pfoh, E.R., Yang, T., Pham, J.C., \& Dy, S.M. (2013). Rapid-response systems as a patient safety strategy: a systematic review. Annals of Internal Medicine, 158, 417-425.

\section{Accepted for Publication August 2018}

Dann, L., \& Hill, J. (2018). Recognising and responding to acutely deteriorating women in New Zealand maternity wards: A literature and environmental scan. New Zealand College of Midwives Journal, 54, 51-57.

https://doi.org/10.12784/nzcomjnl54.2018.7.51-57

Table 2. Summary of the findings of the literature search

\begin{tabular}{|c|c|c|c|c|c|}
\hline $\begin{array}{l}\text { Authors, } \\
\text { Year }\end{array}$ & Research design & Aim & Method & Limitations & Key findings \\
\hline $\begin{array}{l}\text { Austin et al. } \\
(2014) \\
\text { NZ }\end{array}$ & $\begin{array}{l}\text { Retrospective } \\
\text { case review }\end{array}$ & $\begin{array}{l}\text { To determine whether } \\
\text { EWS may have improved } \\
\text { detection of severe } \\
\text { maternal morbidity or } \\
\text { lessened severity of illness }\end{array}$ & $\begin{array}{l}\text { Multidisciplinary team } \\
\text { determined through group } \\
\text { consensus whether EWS might } \\
\text { have improved care }\end{array}$ & $\begin{array}{l}64 \text { charts Non- } \\
\text { modified adult } \\
\text { EWS }\end{array}$ & $\begin{array}{l}\text { Adult EWS may have reduced } \\
\text { severe maternal morbidity in } 5 \\
\text { (7.6\%) cases. } \\
\text { No patient had a complete set of } \\
\text { core vital signs recorded }\end{array}$ \\
\hline $\begin{array}{l}\text { Behling \& } \\
\text { Renaud } \\
\text { (2015) } \\
\text { USA }\end{array}$ & $\begin{array}{l}\text { Pre- and post- } \\
\text { implementation } \\
\text { retrospective case } \\
\text { review of women } \\
\text { with postpartum } \\
\text { haemorrhage }\end{array}$ & $\begin{array}{l}\text { To assess impact of } \\
\text { introducing obstetric } \\
\text { vital sign alert in } \\
\text { electronic health record } \\
\text { and corresponding } \\
\text { escalation pathway }\end{array}$ & $\begin{array}{l}\text { Multi-site pre- and post- } \\
\text { implementation case review } \\
\text { assessing clinical variables, } \\
\text { response time, length of stay }\end{array}$ & $\begin{array}{l}94 \text { charts } \\
\text { Only included } \\
\text { postpartum } \\
\text { haemorrhage }\end{array}$ & $\begin{array}{l}\text { Response time and time to } \\
\text { intervention significantly improved } \\
\text { in post-implementation cohort. } \\
\text { Total estimated blood loss was } \\
\text { significantly reduced. }\end{array}$ \\
\hline $\begin{array}{l}\text { Bick et al. } \\
(2014) \\
\text { UK }\end{array}$ & $\begin{array}{l}\text { Cross-sectional } \\
\text { survey }\end{array}$ & $\begin{array}{l}\text { To identify variation in } \\
\text { the use of maternity EWS }\end{array}$ & $\begin{array}{l}\text { Survey electronically distributed } \\
\text { to heads of midwifery at NHS } \\
\text { maternity care facilities ( } n=157) \text {; } \\
68 \% \text { response rate }\end{array}$ & $\begin{array}{l}\text { Subjective } \\
\text { reporting of } \\
\text { organisational } \\
\text { use of maternity } \\
\text { EWS. }\end{array}$ & $\begin{array}{l}\text { All but one facility had introduced } \\
\text { EWS; wide variation in tools, } \\
\text { parameters, thresholds, escalation } \\
\text { procedures. Little evidence of } \\
\text { benefit. }\end{array}$ \\
\hline $\begin{array}{l}\text { Carle et al. } \\
(2013) \\
\text { UK }\end{array}$ & $\begin{array}{l}\text { Retrospective } \\
\text { validation study }\end{array}$ & $\begin{array}{l}\text { To validate statistically } \\
\text { based aggregate } \\
\text { weighted EWS (obstetric) }\end{array}$ & $\begin{array}{l}\text { Retrospective data from } 4,440 \\
\text { patients admitted to critical care } \\
\text { units }\end{array}$ & $\begin{array}{l}\text { Score validated } \\
\text { using data set } \\
\text { from critical } \\
\text { care patients. }\end{array}$ & $\begin{array}{l}\text { The obstetric EWS performed well } \\
\text { in discriminating survivors from } \\
\text { non-survivors }\end{array}$ \\
\hline $\begin{array}{l}\text { Edwards et } \\
\text { al. (2015) } \\
\text { USA }\end{array}$ & $\begin{array}{l}\text { Retrospective } \\
\text { cohort study using } \\
\text { prospectively } \\
\text { collected clinical } \\
\text { observations }\end{array}$ & $\begin{array}{l}\text { To compare diagnostic } \\
\text { performance of six } \\
\text { EWS for women with } \\
\text { severe sepsis due to } \\
\text { chorioamnionitis. Three } \\
\text { EWS used single- } \\
\text { parameter triggers, three } \\
\text { used aggregate scores }\end{array}$ & $\begin{array}{l}364 \text { cases with complete } \\
\text { data from a single tertiary } \\
\text { unit reviewed. Retrospectively } \\
\text { applied all six EWS to determine } \\
\text { sensitivity, specificity, positive } \\
\text { predictive value }\end{array}$ & $\begin{array}{l}\text { Focussed } \\
\text { specifically on } \\
\text { sepsis due to } \\
\text { chorioamnionitis }\end{array}$ & $\begin{array}{l}\text { Positive predictive value low } \\
\text { for all six scores (<2-15\%). Single } \\
\text { parameter systems more sensitive; } \\
\text { aggregate scoring systems more } \\
\text { specific }\end{array}$ \\
\hline $\begin{array}{l}\text { Hedriana } \\
\text { et al. (2016) } \\
\text { USA }\end{array}$ & $\begin{array}{l}\text { Retrospective } \\
\text { case control study }\end{array}$ & $\begin{array}{l}\text { To compare triggers for } \\
\text { six vital sign parameters } \\
\text { to predict pregnancy } \\
\text { morbidity }\end{array}$ & $\begin{array}{l}\text { Retrospective chart review of } \\
\text { ICU obstetric patients looking at } \\
\text { frequency and intervals of vital } \\
\text { sign triggers in comparison to } \\
\text { control group of normal obstetric } \\
\text { patients }\end{array}$ & $\begin{array}{l}\text { Obstetric } \\
\text { patients in } \\
\text { ICU }(n=50) \text {, } \\
\text { control obstetric } \\
\text { patients with } \\
\text { uncomplicated } \\
\text { deliveries }(n=50)\end{array}$ & $\begin{array}{l}\text { At least one persistent vital sign } \\
\text { trigger (lasting } \geq 30 \text { mins) present } \\
\text { in almost three quarters of women } \\
\text { transferred to ICU, compared to } \\
<5 \% \text { of uncomplicated obstetric } \\
\text { patients. }\end{array}$ \\
\hline $\begin{array}{l}\text { Hess et al. } \\
\text { (2017) } \\
\text { USA }\end{array}$ & $\begin{array}{l}\text { Electronic } \\
\text { modelling } \\
\text { comparing } \\
\text { outcomes \& costs } \\
\text { before \& after } \\
\text { implementation of } \\
\text { maternity EWS }\end{array}$ & $\begin{array}{l}\text { To assess cost- } \\
\text { effectiveness of } \\
\text { maternity EWS in } \\
\text { reduction of severe } \\
\text { maternal morbidity } \\
\text { (SMM) }\end{array}$ & $\begin{array}{l}\text { Developed decision-analytic } \\
\text { model and applied it to } \\
\text { theoretical cohort of } 4 \text { million } \\
\text { women assessing clinical } \\
\text { outcomes and cost effectiveness } \\
\text { based on factors derived from } \\
\text { the literature }\end{array}$ & $\begin{array}{l}\text { Theoretical } \\
\text { modelling }\end{array}$ & $\begin{array}{l}\text { Maternity EWS appears to be cost- } \\
\text { effective strategy to reduce SMM } \\
\text { during maternity hospitalisations }\end{array}$ \\
\hline
\end{tabular}




\begin{tabular}{|c|c|c|c|}
\hline $\begin{array}{l}\text { Isaacs et } \\
\text { al. (2014) } \\
\text { UK }\end{array}$ & Survey & $\begin{array}{l}\text { To explore early warning } \\
\text { systems used in maternity } \\
\text { units in UK }\end{array}$ & $\begin{array}{l}\text { Electronic questionnaire sent to } \\
205 \text { lead obstetric anaesthetists; } \\
63 \% \text { response rate }\end{array}$ \\
\hline
\end{tabular}

Subjective

reporting of

organisational

use of maternity EWS
91\% agreed obstetric EWS helped prevent morbidity. Despite variation in tools \& parameters used, general agreement that most important in EWS are respiratory rate, heart rate, temperature, systolic/ diastolic blood pressure, $\mathrm{O}^{2}$ saturation.
Mackintosh Ethnographic et al. (2014) study

UK

\section{To explore}

implementation of an obstetric EWS
Observations, semi structured interviews and document review in two maternity services. Data thematically analysed
Generalisability

may be

problematic

outside of UK settings EWS enabled communication, helped shape shared understanding of maternal complications. However midwives and obstetricians questioned perceived increase in workload associated with using chart. given low incidence of maternal complications.

\begin{tabular}{ll}
\hline $\begin{array}{l}\text { Maguire et } \\
\text { al. (2015) } \\
\text { Ireland }\end{array}$ & $\begin{array}{l}\text { Mixed } \\
\text { retrospective and } \\
\text { prospective single } \\
\text { centre study }\end{array}$ \\
\hline $\begin{array}{l}\text { Maguire et } \\
\text { al. (2016) } \\
\text { Ireland }\end{array}$ & $\begin{array}{l}\text { Observational } \\
\text { study of women } \\
\text { admitted to } \\
\text { the HDU after } \\
\text { implementation } \\
\text { of Irish national } \\
\text { obstetric EWs }\end{array}$ \\
\hline $\begin{array}{l}\text { Martin } \\
\text { (2015) }\end{array}$ & $\begin{array}{l}\text { Grounded theory } \\
\text { UK }\end{array}$
\end{tabular}

To assess whether Irish maternity EWS vital signs improved the recording for women with bacteraemia

To explore whether the Irish maternity EWS contributed to earlier identification of women with severe maternal morbidity

To understand midwives' experiences of using a modified EWS

$\begin{array}{ll}\text { IMEWS retrospectively applied to } & \text { Small numbers } \\ \text { records of vital signs over six-year } & \text { in prospective } \\ \text { period. The prospective over a } & \text { cases } \\ \text { 12-month period. } & \end{array}$
Introduction of IMEWS for women with bacteraemia associated with improved recordings of vital signs, particularly respiratory rate.
UK

\begin{tabular}{|c|c|}
\hline $\begin{array}{l}\text { Ryan et } \\
\text { al. (2017) } \\
\text { Canada }\end{array}$ & $\begin{array}{l}\text { Retrospective } \\
\text { observation case } \\
\text { control validation } \\
\text { investigating } \\
\text { physiological } \\
\text { predictors of ICU } \\
\text { admission }\end{array}$ \\
\hline $\begin{array}{l}\text { Shields et } \\
\text { al. (2016) } \\
\text { USA }\end{array}$ & $\begin{array}{l}\text { Before and after } \\
\text { study }\end{array}$ \\
\hline
\end{tabular}

$\begin{array}{lll}\begin{array}{l}\text { Case review of } 167 \text { women } \\ \text { admitted to HDU in one tertiary } \\ \text { hospital }\end{array} & \begin{array}{l}\text { Of cases } \\ \text { reviewed }<50 \% \\ \text { of women had } \\ \text { IMEWS charts } \\ \text { completed }\end{array} & \begin{array}{l}80 \text { cases had IMEWS chart } \\ \text { completed prior to HDU } \\ \text { admission. Of those, } 73.9 \% \text { were } \\ \text { triggered by IMEWS and } 26.3 \% \text { by } \\ \text { clinical judgement }\end{array}\end{array}$

Six semi-structured interviews
with midwives working on labour
ward of a single tertiary teaching
centre

Generalisability Frequent changes in practice, in smaller lack of training, duplication of maternity documentation perceived as facilities and barriers. Tool seen as threat to outside of the autonomy, undermining clinical UK judgement.

To evaluate Comparing physiological Small numbers

Trigger had high sensitivity but low specificity for ICU admission If more than one extreme trigger present, system maintained sensitivity and improved specificity early obstetric warning ICU admission for 46 women system to predict ICU against 138 randomly selected admission control maternity patients in two maternity settings. 13 single parameter triggers

Early assessment and treatment of patients with suspected deterioration. To address four most common causes of maternal morbidity

Earl

\section{Prospective data collection} over 13-month period after implementation of Maternal Early Warning Trigger (MEWT) tool, compared to 24 months pre-implementation baseline. Single-parameter system requires triggers to be sustained for >20mins. Included 36,832 women at pilot sites: 24,221 pre- and 12,611 post-implementation. MEWT included key components of clinical pathways for the 4 conditions

\begin{tabular}{ll}
\hline Singh et al. & Prospective \\
$(2012)$ & review
\end{tabular}

UK

$\begin{array}{ll}\begin{array}{l}\text { To evaluate modified } \\ \text { early obstetric warning } \\ \text { system (MEOWS) as tool } \\ \text { for predicting maternal } \\ \text { morbidity, measuring } \\ \text { sensitivity, specificity and } \\ \text { predictive value }\end{array} & \begin{array}{l}\text { completion of MEOWS charts } \\ \text { for triggers and evidence of } \\ \text { trigger system }\end{array} \\ \begin{array}{ll}\text { To analyse early warning } \\ \text { charts in consultant- }\end{array} & \begin{array}{l}120 \text { obstetric early warning } \\ \text { charts and escalation protocols } \\ \text { led maternity units to } \\ \text { establish vital sign values } \\ \text { and presence of explicit } \\ \text { escalation }\end{array} \\ \end{array}$

No admissions study period

\section{Charts only} available from consultant-led maternity units to ICU during
200 triggered, with 86 having morbidity according to criteria. MEOWS $89 \%$ sensitive and $79 \%$ specific, positive predictor value $39 \%$, negative predictor value $98 \%$

Considerable variation in escalation charts and protocols, e.g. 75 discrete combinations of vital sign ranges 